\title{
Improving Chemigation Systems Efficiency Under Arid Conditions Based on Weighing-Points Technique
}

\author{
Yasser E Arafa ${ }^{1 *}$ and Khaled A Shalabi ${ }^{2}$
}

${ }^{1}$ Agricultural Engineering Department, Faculty of Agriculture, Ain Shams University, Egypt

${ }^{2}$ On-Farm Irrigation Engineering Department, Agricultural Engineering Research Institute, ARC, Egypt

\begin{abstract}
Although, chemigation systems is usually used to ensure stable productivity of crop-unit area and improve yieldquality, but on the other hands, it represent a serious problem for applying such systems, as well as, its impact on either yield production and attributed quality parameters or agricultural physical resources. The abovementioned, corresponded problems could be avoided, even and even so, good management practices had been considered for all parts of chemigation systems, i.e. irrigation systems; water and agro-chemical injecting equipment; soil management and crop considerations. Management of a chemigation system requires a highly-qualitative database of the available resources and corresponding field status and conditions. Therefore, for solving the abovementioned problems, weighing-points technique may play a crucial role and can be an effective tool which can be used efficiently. Hereby, the aim of this study was to build, verify and validate a proto type-rule of weighing-point technique for managing chemigation systems under arid ecosystem conditions of Egyptian agriculture. Results indicated that there was a highly significant correlation degrees ranging from 86.39 up to $95 \%$ of the observed field data vs estimated one response to the variants in chemigation management. Hereby, weighing point technique has an integrity to observe a good chemigation practices in such extreme cases ad anticipated variables and qualifiers.
\end{abstract}

Keywords: Chemigation; Fertigation; Irrigation systems; Management criteria; Soils; Vegetable crops

\section{Introduction}

The influence of specific factors such as agrochemical properties, environmental conditions and amount of water needs on the chemigation systems efficiency had been clarified by El-Gindy [1,2]. However, He reported that, agrochemicals with high water solubility are carried to a deeper depth than are those low solubility. Solubility also affects the amount of chemicals availability for adsorption from the soil solution by plants. Adsorption is important to the activity and persistence of herbicides in soil; it varies among herbicides and soils. Also, He stated that if herbicide solution is to be applied throughout or during the last part of irrigation, the trickle irrigation system must be operated for a sufficient time (usually about is minutes) after the injection is finished to completely flush the herbicide from the system. With this regard Arafa et al. [3] reported some criteria for effective management of chemigation systems under arid ecosystems conditions. However, they stated that soil properties must be considered in agrochemicals selection, regardless of the application method. Soil texture and organic matter influence the performance of soil applied chemicals and are especially important with herbicides used in irrigation water. Generally, soil moisture influences the penetration of irrigation water and therefore influences the, movement of applied chemicals into the soil. On dry soil, water penetration and chemicals movement are less than with moist soil. The amount of water used to apply may affect the distribution, movement, persistence and efficacy of the applied agrochemicals. Crop tolerance to the chemicals may also be affected; if too much water is used, the chemicals may leach too deeply and injure the crop. On the other hand, if little water amounts are used, the chemicals maybe distributed unevenly or may not be moved into the soil adequately and target will not be gotten. In addition, the optimum amount of water for applying agro-chemicals in irrigation water will depend upon chemicals properties, soil texture, soil moisture, soil organic matter, the crop and the aims to be desired. Abdel-Aziz [4] found that although the same fertilizer concentration was used in injector stock solution, the results exhibit different fertilizer concentrations for both the fertigation devices and lateral lengths. Also, he found that the highest fertilizer distribution uniformity with the hydraulic pump, followed by the venturi, while the lowest were fertilizer distribution uniformity with the differential pressure tank. With this point of view, new techniques such as fertigation, herbigation and other were developed to describe the various types of chemigation [5-7]. Chemigation can be used with different types of irrigation systems such as: i) Many dry, liquid and liquid-suspension fertilizer materials are suitable for application through trickle and sprinkler irrigation systems. The main criteria used in selecting of fertilizer materials are the solubility, convenience, and cost of the desired nutrients; and ii) Clear liquid fertilizers contain nutrients in solution. Thus, they are very convenient to handle with pump and gravity flow from bulk storage tank for injection into the irrigation water. Liquid fertilizers may contain a single nutrient or combinations of nitrogen, phosphate, and potassium. Dry fertilizer products may be dissolved by mixing with water in a separate open tank in the approximate ratio about one $\mathrm{kg}$ of fertilizer to 8 liter of water and then, pumped into an irrigation pipe.

Schutze et al. reported that citrus production in central Florida depends on the management of sandy soil with very low water and nutrient holding capacities. Significant numbers of sacrificial aquifers used for drinking water have become contaminated with nitrates in excess of the mandated maximum contamination level of $10 \mathrm{mg}$ for drinking water. Also, they stated that specific date and duration of each irrigation event will be determined for each irrigation block. The long-term sustainability of citrus production on the sandy soil of central Florida is dependent on the ability of producers to efficiently use limited water resources for optimal production while reducing environmental impacts.

*Corresponding author: Yasser E Arafa, Agricultural Engineering Department Faculty of Agriculture, Ain Shams University, Egypt, Tel: +20 2 26831474; E-mail: arafayeh11@gmail.com

Received July 04, 2016; Accepted November 14, 2016; Published November 16,2016

Citation: Arafa YE, Shalabi KA (2016) Improving Chemigation Systems Efficiency Under Arid Conditions Based on Weighing-Points Technique. J Civil Environ Eng 6: 257. doi: 10.4172/2165-784X.1000257

Copyright: ( 2016 Arafa YE, et al. This is an open-access article distributed under the terms of the Creative Commons Attribution License, which permits unrestricted use, distribution, and reproduction in any medium, provided the original author and source are credited. 
Hereby, the aim of this work was a trial to use weighing-points technique as a tool for managing chemigation systems under arid ecosystem conditions.

\section{Materials and Methods \\ Identification of chemigation systems management therapy}

Soils: different soils properties and attributed characteristics under diverse filed conditions had been taken into considerations. These variables are physical, hydro physical and chemical properties, soil texture, chemical analysis of different macro and micro-elements (total available and depletion had been considered for managing chemigation with respect to validated crops chemical requirements.

Irrigation method and attributed systems: which are widely used under Egyptian conditions had been investigated either hydraulic or performance analysis). Regarding irrigation methods and attributed systems, sprinkler, (solid)-set, hand movable, floppy and center pivot); localized (surface and subsurface trickle, mini-sprinkler, bubbler and low-head-gravity flow-bubbler) and gravity (modified surface based an get pipes techniques.

Agro-chemical injections and their performance analysis criteria: there widely agro-chemicals injectors used had been investigated (pressure differential tank, verturi devices and positive displacement pump electrical dozen in commercial issue"). However, different criteria had been considered for investigation purpose, such as: technical considerations (application rate, position of placement. Solution concentration and injection timing) and other agronomic considerations (chemigation, crop types, types of applied materials).

Crop patterns and types: different crop patterns and types had been selected for validation purposes of the expert systems for instance. Form orchards (citrus, mango, peach, and grapes); form vegetables (tomato, green beans, peas, potato, and strawberry); and form filed crops (zea maize, faba bean and wheat). However, these crops had been selected due to first strategic and economic aspects and due to it cultivation area are great, Also, there were selected due to their positive responses for growing in wide range of Egyptians macro and micro climate and soil conditions old loads and newly reclined area.

Applied materials: Different categories of applied material that widely used under arid conditions had been investigation. However, the agro chemical materials are generally classified (based on application made of action) fertilizers and pesticides. The macronutrients are $\mathrm{N}, \mathrm{P}$ and $\mathrm{K}$ they appeared in the Egyptian market and their scientific characteristics had been taken into considerations for managing chemigation technology and attributed techniques.

\section{Identification of Weighing-Points Therapy}

The process of defining the dynamic network structure which involves information analysis and identifying of the decision making process and activities related to the application priorities of chemigation systems management under extreme field resources had been illustrated based on the principle of information engineering used together a reference information model for arable farming. A dynamic network is characterized by inherent uncertainty. Specifying nodes and dependencies in the model and a quantitative step which specifying conditional probabilities, as shown in Figure 1. Based on this information model, building network blocks of the dynamic network model are set up as a random variables ranging over possible states, observations, actions and relations between these criteria variables parameters factors and indices Representing the temporal aspects of the chemigation management problem, sequences of the relevant variables are used to present probabilities at successive time points under diverse physical farm resources and situations, devotes to the management process at a particular point in status. Quantification of the network implies the specification of the conditional probabilities for each node in the network. For each combination of values for the parent of a node an experiment (represented by weighing-balance scores) is set up corresponding to that combination and then the value of the node of the interest is determined. Evaluation of qualifier criteria and key parameters were transformed as score point. These scoreweighing balances are used for evaluation procedure of the application priorities process and analysis of chemigation technology. Wherever, the weighing-balance virtual score method has the successive in judgment on the chemigation management procedures systems under different choices according to different qualifiers and farm situations and conditions. The assumption of weighing-balance scores was based on the experiences and judgment of authors and domain experts. Also, some of these scores were extracted from the on-farm irrigation engineering and agro-chemical literatures and scientific publications of chemigation, M. Sci. and Ph. D. Thesis's, as well as, on-farm irrigation projects [8-15].

\section{Evaluation of Chemigation Systems}

Fields evaluation is very important to both the irrigator and chemigation for deciding if the system can be operated efficiency and whether it can be improved. For any irrigation system, the uniformity and efficiency of using both water and fertilizers by growing plants are of major importance. The variation or non-uniformity of emitter discharge in trickle irrigation system is the result of number of factors. The most important of these factors is the hydraulic variation and emitter discharge variation.

Several methods for describing uniformity of water application have been used in trickle work; some are based on modification of Christiansen's definition for the evaluation of the uniformity of sprinkler irrigation, and other relate average discharge rate to a range of the preselected discharge rates within the flow. Statistical uniformity concept that depends on the total coefficient of variation for distributor discharges [16].

Uniformity of distribution and controlled water applications are of major technical prerequisites for good irrigation, and chemigation management. However, the systematic errors in chemical application rate had to be in the range of 10 to $16 \%$. The relationship between the minimum and the average discharge of the discharge of the distributors was defined as the emission uniformity (EU). They use in the design procedure as an efficiency concept for computing the gross irrigation depth, the irrigation interval, the required system capacity and the selection of the type of distributor. Hereby, the initial evaluation of the investigated injectors under field conditions could be illustrated in Figure 2.

\section{Formalization of weighing-points technique}

Bayesian theory had been used for deciding the appropriate method for calculating the weighing points for each criteria, variables, parameters; and factors. However, Bayes' Theorem, developed by the Rev. Thomas Bayes, 18th century mathematician and theologian. Mathematically it is expressed as:

$$
P(\mathrm{H} \backslash \mathrm{E}, \mathrm{c})=\frac{P(\mathrm{H} \backslash \mathrm{c}) * \mathrm{P}(\mathrm{E} \backslash \mathrm{H}, \mathrm{c})}{P(\mathrm{E} \backslash \mathrm{c})}
$$

Where we can update our belief in hypothesis $\mathrm{H}$ given the additional evidence $\mathrm{E}$ and the background context $\mathrm{c}$. The left-hand term, 


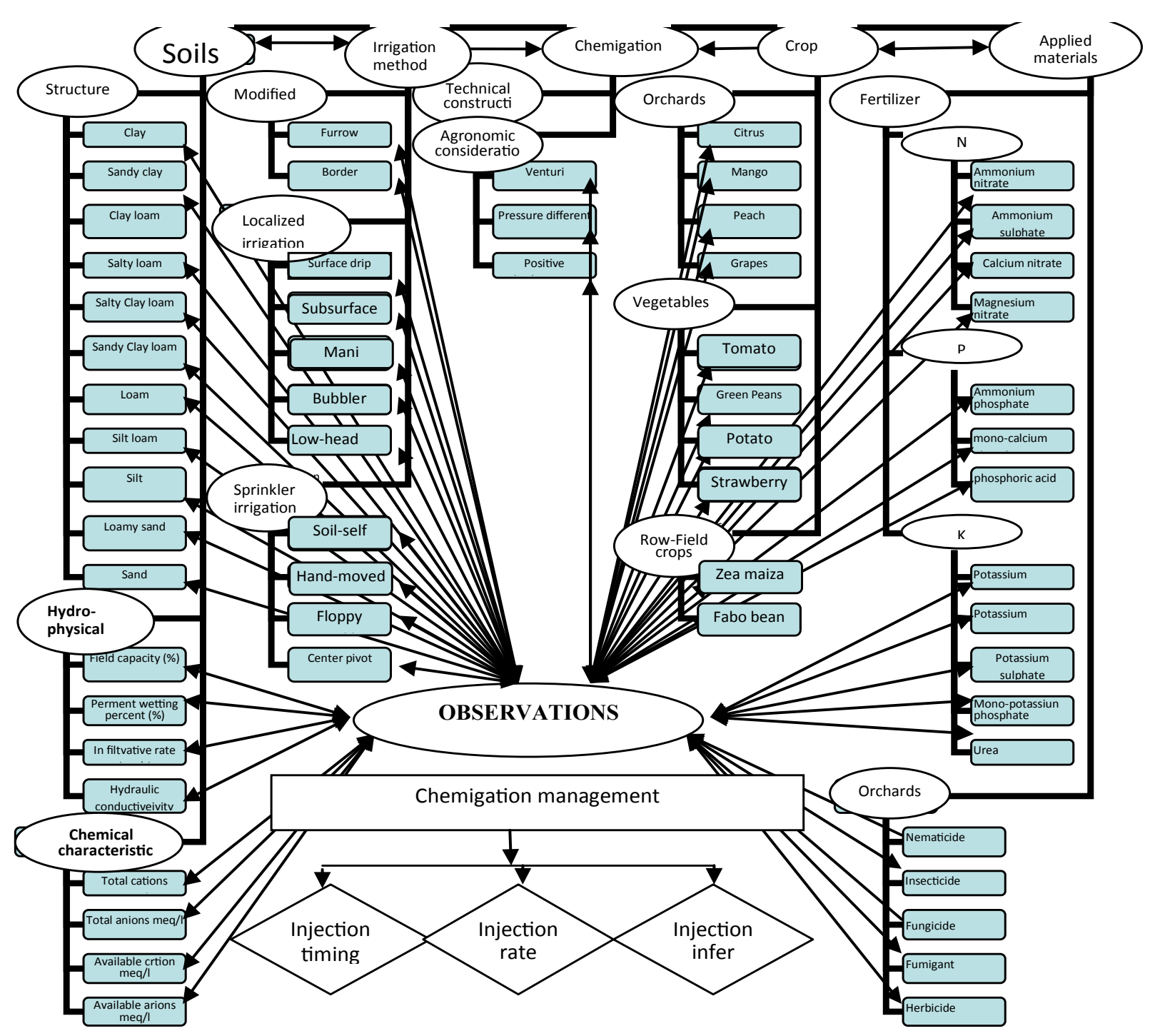

Figure 1: Bayesian network for chemigation systems management:

*The conventions followed in the diagram are:

- Ellipses indicate random variables and their probability distributions

- Ellipse marked "observations" indicates the results of observations

- Squares indicate decisions

- Diamonds represents utilities

- Edges indicate condition dependencies

$\mathrm{P}(\mathrm{H} \mid \mathrm{E}, \mathrm{c})$ is known as the "posterior probability," or the probability of $\mathrm{H}$ after considering the effect of $\mathrm{E}$ on $\mathrm{c}$. The term $\mathrm{P}(\mathrm{H} \mid \mathrm{c})$ is called the "prior probability of $\mathrm{H}$ given $\mathrm{c}$ alone. The term $\mathrm{P}(\mathrm{E} \mid \mathrm{H}, \mathrm{c})$ is called the "likelihood" and gives the probability of the evidence assuming the hypothesis $\mathrm{H}$ and the background information $\mathrm{c}$ is true. Finally, the last term $\mathrm{P}(\mathrm{E} \mid \mathrm{c})$ is independent of $\mathrm{H}$ and can be regarded as a normalizing or scaling factor. It is important to note that all of these probabilities are conditional. They specify the degree of belief in some proposition or propositions based on the assumption that some other propositions are true. As such, the theory has no meaning without prior resolution of the probability of these antecedent propositions. Formalization involved characterizing the key factors into a representation usable within the environmental development of chemigation systems management. However, the knowledge base was digitalized by fuzzy set theory, as shown in Table 1. The qualitative data of the chemigation technology management were gathered, analyzed and refined and it was come from the literature reviews, field requirements and expert experiences in previous [17-19].

\section{Results and Discussion}

An appropriate application of different chemigation equipment pressure differentia tank, venturi and positive displacement pumps) under divers filed conditions comprise between different chemigation equipment (had been investigated based on the qualifier criteria. Virtual weighing, balance scores were used in the validation process of the developed rule-based program, wherever each chemical injector type was weighted under each qualifier based on the domain expert therapy. Different case studies, represent technical considerations (irrigation systems, chemical injector type and placement position, crop patterns and chemigated area) had been investigated and the outputs data of devised expert system on the effective chemigation 


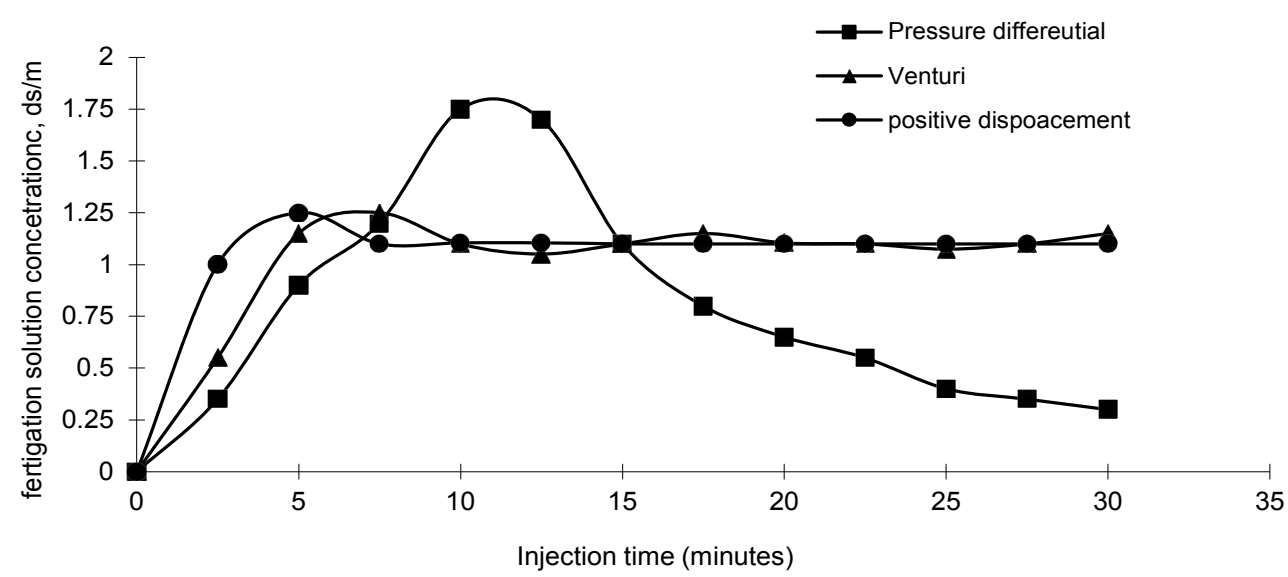

Figure 2: Initial evaluation of chemigation injectors under field conditions.

\begin{tabular}{|c|c|c|c|c|c|c|c|c|}
\hline \multirow{3}{*}{ Criteria } & \multirow{3}{*}{ Qualifiers } & \multirow{3}{*}{ Variables } & \multicolumn{6}{|c|}{ Injector types and position of installation } \\
\hline & & & \multicolumn{2}{|c|}{ Pressure Differential } & \multicolumn{2}{|c|}{ Venturi } & \multicolumn{2}{|c|}{ Positive Displacement } \\
\hline & & & $\mathbf{i}$ & ii & i & ii & i & ii \\
\hline \multirow{15}{*}{$\begin{array}{c}\text { Technical } \\
\text { considerations }\end{array}$} & \multirow{8}{*}{ Irrigation system } & solid-set-sprinkler & 10 & 20 & 20 & 23 & 23 & 18 \\
\hline & & Hand-movement & 20 & 23 & 22 & 25 & 22 & 17 \\
\hline & & Floppy & 15 & 10 & 14 & 14 & 23 & 15 \\
\hline & & Center pivot & 0 & 0 & 0 & 0 & 25 & 0 \\
\hline & & Surface and subsets face drop & 20 & 21 & 21 & 21 & 20 & 17 \\
\hline & & Mini-sprinkler & 20 & 22 & 18 & 18 & 20 & 17 \\
\hline & & Bubbler & 10 & 22 & 15 & 15 & 19 & 15 \\
\hline & & Low-head-bubbler & 10 & 22 & 15 & 15 & 19 & 15 \\
\hline & \multirow{3}{*}{$\begin{array}{l}\text { Desert chemical } \\
\text { concentration }\end{array}$} & Low & 12 & 15 & 15 & 15 & 0 & 0 \\
\hline & & Medium & 10 & 15 & 15 & 15 & 7 & 7 \\
\hline & & High & 0 & 0 & 7 & 7 & 15 & 15 \\
\hline & \multirow{2}{*}{ Available injection time } & Sufficient & 10 & 10 & 10 & 10 & 10 & 10 \\
\hline & & Sheet & 0 & 5 & 10 & 10 & 10 & 10 \\
\hline & \multirow{2}{*}{ Applied materials } & Fertilizer & 0 & 10 & 10 & 10 & 10 & 10 \\
\hline & & Pesticides & 0 & 0 & 5 & 7 & 10 & 10 \\
\hline & & & 0 & 4 & 5 & 6 & 7 & 7 \\
\hline & & i: At central Control Hea & At near & & & & & \\
\hline \multirow{6}{*}{ Chemigated area } & \multirow{3}{*}{ Chemigated area } & Large size & 4 & 4 & 4 & 3 & 0 & 2 \\
\hline & & Medium size & 4 & 4 & 4 & 3 & 2 & 3 \\
\hline & & Small size & 4 & 4 & 4 & 4 & 4 & 4 \\
\hline & \multirow{2}{*}{ Labor expert } & High & 4 & 4 & 4 & 4 & 4 & 4 \\
\hline & & Low & 0 & 0 & 0 & 0 & 0 & 0 \\
\hline & Clogging resistance & Ability of irrigation system & 6 & 6 & 5 & 5 & 7 & 4 \\
\hline \multirow{4}{*}{ Potential costs } & \multirow{2}{*}{ Energy power source } & Electrical & 10 & 10 & 10 & 10 & 10 & 10 \\
\hline & & Diesel & 8 & 8 & 8 & 7 & 10 & 7 \\
\hline & \multirow{2}{*}{ Labor availability } & Abundant & 5 & 5 & 5 & 5 & 5 & 5 \\
\hline & & Scare & 4 & 4 & 4 & 3 & 1 & 3 \\
\hline \multirow{3}{*}{ Energy } & \multirow{3}{*}{ Energy saving } & \multirow{2}{*}{ High } & 5 & 5 & 3 & 3 & 5 & 3 \\
\hline & & & 8 & 8 & 8 & 8 & 8 & 8 \\
\hline & & Low & 4 & 4 & 3 & 3 & 7 & 4 \\
\hline
\end{tabular}

Table 1: Decision table based on weighing-points scores for managing chemigation systems under diverse for conditions.

technology management. Also, statistical analysis had been taken into considerations for the evaluation processes.

\section{Effect of irrigation system on the chemigation systems efficiency}

Irrigation system and its hydraulic performance analysis play a crucial role in improvement chemigation management efficiencies. However, the energy of pumping irrigation water is available under priorities of chemical injectors are tabulated in Tables 2 and 3 . With respect to sprinkler irrigation systems, data analysis indicate that either positive displacement pumps or venturi devices can be used successfully within a wide range of field conditions. However, there are in agreement with that had been observed by the domain expert. In addition, these findings are in logic in judgments and have the potentiality advantages in application in order to improve the chemigation efficiency. For solid-set sprinkler irrigation system, data of the application practices of each chemical injector type revealed as 


\begin{tabular}{|c|c|c|c|c|c|}
\hline \multirow{2}{*}{ Irrigation system } & \multirow{2}{*}{ Chemigated area } & \multirow{2}{*}{ Dominant test method } & \multicolumn{3}{|c|}{ Chemical injector type } \\
\hline & & & A & B & C \\
\hline \multirow{6}{*}{ Solid-set } & \multirow{2}{*}{ Small size ( $\leq 2 \mathrm{fed})$} & Weighing-point output & 85 & 85 & 85 \\
\hline & & Field measurements & 85 & 90 & 91 \\
\hline & \multirow{2}{*}{ Medium size $(2-5$ fed $)$} & Weighing-point output & 84 & 84 & 87 \\
\hline & & Field measurements & 75 & 90 & 90 \\
\hline & \multirow{2}{*}{ Large size ( $\geq 5$ fed) } & Weighing-point output & 70 & 80 & 90 \\
\hline & & Field measurements & 77 & 91 & 96 \\
\hline \multirow{6}{*}{ Hand-movable } & \multirow{2}{*}{ Small size $(\leq 2$ fed $)$} & Weighing-point output & 85 & 96 & \\
\hline & & Field measurements & 87 & 95 & 85 \\
\hline & \multirow{2}{*}{ Medium size (2-5 fed) } & Weighing-point output & 85 & 96 & 95 \\
\hline & & Field measurements & 75 & 96 & 96 \\
\hline & \multirow{2}{*}{ Large size ( $\geq 5$ fed) } & Weighing-point output & 60 & 96 & 96 \\
\hline & & Field measurements & 60 & 92 & 92 \\
\hline \multirow{6}{*}{ Floppy-sprinkler } & \multirow{2}{*}{ Small size $(\leq 2 \mathrm{fed})$} & Weighing-point output & 71 & 83 & 92 \\
\hline & & Field measurements & 72 & 87 & 95 \\
\hline & \multirow{2}{*}{ Medium size (2-5 fed) } & Weighing-point output & 70 & 86 & 94 \\
\hline & & Field measurements & 60 & 85 & 86 \\
\hline & \multirow{2}{*}{ Large size ( $\geq 5 \mathrm{fed}$ ) } & Weighing-point output & 70 & 89 & 96 \\
\hline & & Field measurements & 71 & 92 & 93 \\
\hline
\end{tabular}

Table 2: Application priorities of chemical injectors under different technical parameters for sprinkler irrigation systems.

\begin{tabular}{|c|c|c|c|c|c|}
\hline \multirow{2}{*}{ Irrigation system } & \multirow{2}{*}{ Chemigated area } & \multirow{2}{*}{ Dominant test method } & \multicolumn{3}{|c|}{ Chemical injector type } \\
\hline & & & A & B & C \\
\hline \multirow{6}{*}{ Solid-set } & \multirow{2}{*}{ Small size $(\leq 2 \mathrm{fed})$} & Weighing-point output & 85 & 85 & 85 \\
\hline & & Field measurements & 85 & 90 & 91 \\
\hline & \multirow{2}{*}{ Medium size $(2-5$ fed $)$} & Weighing-point output & 84 & 84 & 87 \\
\hline & & Field measurements & 75 & 90 & 90 \\
\hline & \multirow{2}{*}{ Large size ( $\geq 5$ fed) } & Weighing-point output & 70 & 80 & 90 \\
\hline & & Field measurements & 77 & 91 & 96 \\
\hline \multirow{6}{*}{ Hand-movable } & \multirow{2}{*}{ Small size $(\leq 2 \mathrm{fed})$} & Weighing-point output & 85 & 96 & 96 \\
\hline & & Field measurements & 87 & 95 & 85 \\
\hline & \multirow{2}{*}{ Medium size (2-5 fed) } & Weighing-point output & 85 & 96 & 95 \\
\hline & & Field measurements & 75 & 96 & 96 \\
\hline & \multirow{2}{*}{ Large size ( $\geq 5$ fed) } & Weighing-point output & 60 & 96 & 96 \\
\hline & & Field measurements & 60 & 92 & 92 \\
\hline \multirow{6}{*}{ Floppy-sprinkler } & \multirow{2}{*}{ Small size ( $\leq 2 \mathrm{fed})$} & Weighing-point output & 71 & 83 & 92 \\
\hline & & Field measurements & 72 & 87 & 95 \\
\hline & \multirow{2}{*}{ Medium size (2-5 fed) } & Weighing-point output & 70 & 86 & 94 \\
\hline & & Field measurements & 60 & 85 & 86 \\
\hline & \multirow{2}{*}{ Large size ( $\geq 5$ fed) } & Weighing-point output & 70 & 89 & 96 \\
\hline & & Field measurements & 71 & 92 & 93 \\
\hline
\end{tabular}

Table 3: Application priorities of chemical injectors under localized irrigation systems.

agreement between the domain expert and developed expert system. However, the virtual weighing balance scores indicated that there are a highly regression easily under medium and large scale chemigated area $\left(\mathrm{R}^{2}=0.9671\right)$. On the other hand, under small scale chemigated area, the regression factor $\left(R^{2}\right)$ of about. 0.8211 had been observed. For other hand-movable or floppy sprinkler irrigation system, data of the regression analysis revealed a factor of about 0.9827 . These findings gave the majority for applying the developed expert system in judging of selecting the appropriate chemigation technology equipment under diverse field conditions. On the other hand, date analysis revealed that either pressure differential or venturi had to be applied with mini sprinkler and low-head-gravity flow bubbler with highly restriction and limitations in order to reduce the chemical losses. These outputs lead us to make some concentrations on these systems which can be applied efficiently and maximizing irrigation water and use efficiencies, as well agro-chemical as improving the agricultural physical resources.

\section{Effect of chemical injector type}

The pre-selection process is one of elimination method for analyzing the promising output results. Efficient chemigation method can be used for eliminating the risk hazards and improving the process efficiency. However, data presented in Table 4 and Figure 3, indicated that there was a highly significant correlation degrees ranging from 86.39 up to $95 \%$ of the dominant-test method work response to the variants in chemigation systems management parameters.

Results analysis indicates that for row-field and vegetable crops and due to surface runoff from the property of both bubbler and low-head-gravity flow bubbler irrigation systems will not be allowed for irrigating and chemigation these crops, as well as they are not economically for applied and the illegality for application, especially under the high intake-rate soils as that appears. Given these constraints and limitations, bubbler and low-head-gravity-flow bubbler irrigation 
Citation: Arafa YE, Shalabi KA (2016) Improving Chemigation Systems Efficiency Under Arid Conditions Based on Weighing-Points Technique. J Civil Environ Eng 6: 257. doi: 10.4172/2165-784X.1000257

Page 6 of 6

\begin{tabular}{|c|c|c|c|c|}
\hline \multirow{2}{*}{ Irrigation Method } & \multirow{2}{*}{ Chemigation device } & \multicolumn{2}{|c|}{ Dominant-test method } & \multirow{2}{*}{$\mathbf{R}^{2}$} \\
\hline & & Weighing-points output & Field measurements & \\
\hline \multirow{3}{*}{ Sprinkler } & Pressure differential & 48.8 & 68.4 & 95.9 \\
\hline & Venturi & 50.2 & 71 & 94.55 \\
\hline & Positive displacement & 58 & 78.8 & 86.39 \\
\hline \multirow{3}{*}{ localised } & Pressure differential & 54 & 78 & 94.33 \\
\hline & Venturi & 54 & 79 & 89.93 \\
\hline & Positive displacement & 70 & 87 & 91.53 \\
\hline
\end{tabular}

Table 4: Statistical analysis table for evaluating chemigation systems management.

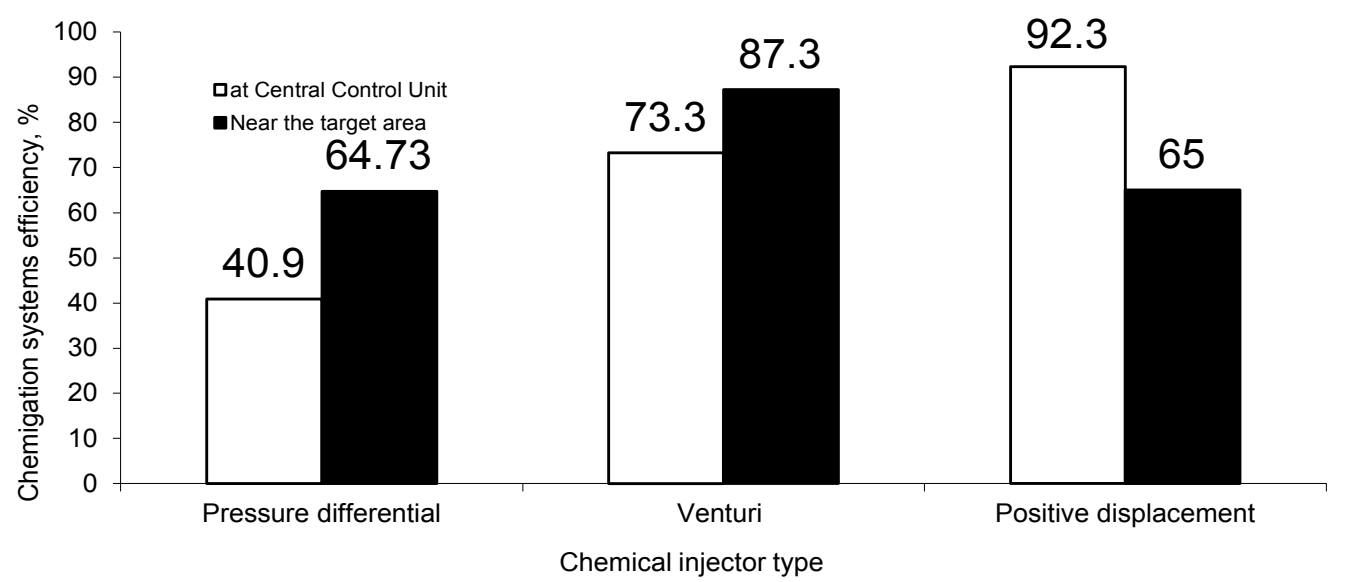

Figure 3: Chemigation systems efficiency under different injector placement positions.

systems are not considered adaptable. Meanwhile, for orchard crops, surface trickle; bubbler and low-head-gravity-flow bubbler irrigation systems would be adaptable. A combination of the applied irrigation system injected type and chemigated area would be other options for application under the above-mentioned conditions, to maximizing agro-chemical use efficiency improving chemical distribution.

\section{References}

1. El-Gindy AM (2002) Study on priorities and sectors of application of modern irrigation systems on old land in Delta and Nile valley, Final Report, Project No. 35, Acad of Sci Res. and Tech, Egypt, 1-8.

2. El-Gindy AM (2002a) Irrigation systems management for organic vegetable production in the Mediterranean basin, Int. short course program on organic agriculture, 20-27 March, Cairo, Egypt, 15-20.

3. Arafa YE, Wasif EA, El-Tantawy MT (2009) Impact of fertigation scheduling on tomato yield under arid ecosystem conditions. J Agric And biological sci 5: 280- 286.

4. Abdel-Aziz AA (2003) Possibility of applying modern irrigation system in the old citrus farms and economic return. J Agric Sci Mansoura Univ 28: 5639-5653.

5. Threadgill ED (1991) Advance of Irrigation/Fertigation and Chemigation, Proc of the Expert Consultation on Chemigation /Fertigation, 8-11 Sept, Cairo, Egypt $156-172$.

6. Steduts P (1984) Fertigation Rivista di Agrononia 18: 3-20 (C.F. Threadgill, Univ. of Georgia, Tifton, GA, 1991a).

7. Stansell JR (1981) Chemigation injectors: Selection, calibration and use. Proc of National Symp. on chemigation, Univ. of Georgia, Tifton, GA 103-108.

8. Arafa YE, Sahhar EA, Rafea AA, Gindy AM (2004) Expert system for application priorities of localized irrigation systems, $9^{\text {th }}$ Conf of Agric Develop. Res., 22-24 March, Fac of Agric, Ain Shams Univ, Cairo, Egypt 208-218.
9. Kady SA (2003) Sprinkler irrigation system management in the Delta valley using the expert system, Ph. D. Thesis, Agric Eng Dept, Fac of Agric, Ain Shams Univ, Cairo, Egypt, 142-143.

10. Awady MN, Sallam MF, Hegazi AM (2002) Expert system approach for selecting mechanized irrigation systems for different situations. Misr J Agric Eng 19: 285-296.

11. Lithy AM (2002) Factors affecting the design of self compensating bubbler for irrigation system, Ph.D. Thesis, Fac. of Agric, Azhar Univ, Egypt, p: 66.

12. Murase $H(2000)$ Artificial intelligence in agriculture. J Comp Elect Agric 16: $1-2$

13. Rafea AA, Shaalan K (1996) Using expert systems as a training tool in the agricultural sector in Egypt. Int J Expert Syst with Applications 12: 183-211.

14. Rafea AA (1998a) Egyptian research program for developing expert systems in agriculture. $7^{\text {th }}$ Int Conf on Comp in Agric, 20-26 July, Orlando, FL, USA, 1028-1046.

15. Sener S, Ozolum U (1991) Turkey's experience in fertigation practices, The Expert Consultation in Chemigation / Fertigation, 8-11 Sept., Cairo, Egypt, 260263.

16. Popov S, Dimirov P, Petrova R, Kalcheva S, Jikov J, et al. (1996) Management information systems in irrigation. $16^{\text {th }}$ Int. Congress on Irrigation and Drainage, Cairo, 71-78.

17. Abou-Khaled A (1991) Fertigation and chemigation an overview with emphasis on the Near East-FAO, Consultation on Fertigation/Chemigation, 8-11 Sept., Cairo, Egypt, 5-21.

18. Rafea AA (1998b) Egyption research program for developing expert systems in Agriculture. $7^{\text {th }}$ Int Conf on Computers in Agriculture, FL, USA, p: 887-904.

19. Schutze N, de paly M; Wohling T, Schmitz GH (2005) Global optimization of deficit irrigation systems using evolutionary Algorithms and neural networks. 1C1D 21 th - Europ. Reg. Conf., May 15-19, Frankfurt (Oder) and Slubice, Germany and Poland 1-9. 